\title{
Formulation and Evaluation of Anti-Acne Lotion Containing Red Ginger (Zingiber officinalle Roscoe) Essential Oil
}

\author{
Dwi Indriati, Ike Y. Wiendarlina, Annisa S. Carolina \\ Faculty of Pharmacy, Pakuan University, Bogor, West Java, Indonesia
}

\begin{abstract}
Red ginger (Zingiber officinalle Roscoe) has been empirically used as antibacterial agent. This study was aimed to formulate anti-acne lotion containing red ginger essential oil and to evaluate its antibacterial activity against Propionibacterium acnes and Staphylococcus epidermidis. Extraction and distillation of $10 \mathrm{~kg}$ of red gingers were performed to obtain its essential oils. The lotions were prepared using oil in water $(\mathrm{o} / \mathrm{w})$ base with various concentration of red ginger essential oils, i.e., $2.5 \%, 5 \%$, and $7.5 \%$. The lotion was assayed to determine organoleptic, homogeneity, $\mathrm{pH}$, viscosity, and irritation-inducing level. Antibacterial activity test was conducted using disk-difussion method. Results indicated that the $7.5 \%$ concentration exerted the strongest activity in inhibiting P. acnes (inhibition zone $12.4 \mathrm{~mm}$ ) and S. epidermidis (inhibition zone $29 \mathrm{~mm}$ ). In conclusion, anti-acne lotion containing $7.5 \%$ of red ginger essential oil was effective to control acne inducing bacteria and fulfilled the required standards.
\end{abstract}

Keywords: Red ginger, essential oil, anti-acne, Propionibacterium acnes, Staphylococcus epidermidis

\section{Introduction}

Acne is one of the most common skin disorders which is characterized by chronic inflammation of pilosebaceous units. Pathogenic mechanism of acne includes increased sebum production, $P$. acnes and $S$. epidermidis colonization, follicular hyperkeratinization, and the products of inflammation. ${ }^{1}$

Red ginger (Zingiber officinalle Roscoe) has been widely studied as a medicinal plant. Its secondary metabolites include flavonoids, phenols, glycosides, triterpenoid, essential oils and tannins. Several previous studies showed that red ginger extract had anti-bacterial activity against $P$. acnes, $S$. epidermidis, $S$. aureus and E. coli. ${ }^{2,3}$ Essential oil of red ginger also exhibited potential anti-bacterial activity against $P$. acnes, $P$. aeruginosa, $S$. aureus, and S. epidermidis. ${ }^{4-6}$

Nevertheless, there is limited

information regarding formulation and evaluation of anti-acne lotion containing red ginger essential oil. Therefore, this study was conducted to formulate anti-acne lotion

Corresponding author: Dwi Indriati. Faculty of Pharmacy, Pakuan University, Bogor, West Java, Indonesia.

Email: dwiindriati@unpak.ac.id

Received: 26 October 2018. Revised: 28 November 2018. Published: 19 December 2018. 
containing red ginger essential oil and to evaluate its anti-bacterial activity against $P$. acnes and S. epidermidis.

\section{Methods}

\section{Materials and instruments}

The materials used in this study included $10 \mathrm{~kg}$ of red ginger, PEG-40 hydrogenated castrol oil (Croduret $50 \mathrm{SS} \AA$ ), caprylic (Crodamol GTCC $\AA$ ), methyl paraben, propyl paraben, glycerin, 96\% ethanol, distilled water, agar media, physiological natrium chloride, $P$. acnes, and $S$. epidermidis cultures. The instruments used included Brookfield viscometer (DV1-Prime $\left.{ }^{\circledR}\right)$, homogenizer (IKA ${ }^{\circledR}$ RW 20 digital), pHmeter, and incubator.

\section{Extraction of essential oil}

Steam distillation was conducted at Bogor Spice and Medicinal Plant Research Center (Balitro) laboratory to obtain red ginger essential oil. A total of $10 \mathrm{~kg}$ of red ginger that had been washed and chopped were placed into a glass flask. Through an inlet, steam was injected to the flask, resulting in the vaporized compounds that subsequently underwent condensation process. The essential oil was then purified by adding $\mathrm{Na}_{2} \mathrm{SO}_{4}$ to eliminate water content. Characteristics of essential oil were examined based on Indonesian National Standard No. 061312-1998.

Formulation of anti-acne lotion

The lotions were prepared using oil in water $(\mathrm{o} / \mathrm{w})$ base with various concentration of red ginger essential oils, i.e., $2.5 \%, 5 \%$, and $7.5 \%$. The formula was based on previous research conducted by Indriati et $a l^{7}$ The oil phase consisted of PEG-40 hydrogenated castrol oil and caprylic, while the water phase consisted of distilled water, methyl paraben, propyl paraben and glycerin. The oil and water phase were heated at $70{ }^{\circ} \mathrm{C}$ and mixed using homogenizer at $500 \mathrm{rpm}$ for 15 minutes. Subsequently, ethanol was added after the temperature decreased. Essential oil was then added and mixed until homogenous.

\section{Anti-bacterial activity test}

Anti-bacterial activity tests against $S$. epidermidis and $P$. acnes were performed using disk-diffusion method. Acnol was used as positive control, while distilled water was used as negative control. $0.5 \mathrm{ml}$ culture containing approximately $10 \times 10^{6}$ bacteria was mixed into agar media solution until homogenous. It was then placed to sterile petri dish until solid. Subsequently, paper disk was placed on the media. Approximately $20 \mu \mathrm{l}$ of lotions were injected on the paper disk. It was then incubated at $35 \pm 2{ }^{\circ} \mathrm{C}$ for 24-48 hours. The inhibition zone was then measured using a ruler. Formula with the best antibacterial activity was assayed to determine its organoleptic, homogeneity, $\mathrm{pH}$, viscosity, and irritation-inducing level. Homogeneity was evaluated by pressing the lotions which was placed on transparent glass with other transparent instrument to

Table 1. Characteristics of Red Ginger Essential Oil

\begin{tabular}{lccl}
\hline \multicolumn{1}{c}{ Testing } & Result & Requirement & Information \\
\hline $\begin{array}{l}\text { Physical testing: } \\
\text { a. Color } \\
\text { b. Odor }\end{array}$ & $\begin{array}{c}\text { Orange } \\
\text { Typical ginger aroma }\end{array}$ & $\begin{array}{c}\text { Yellow - Orange } \\
\text { Typical ginger aroma }\end{array}$ & $\begin{array}{l}\text { Qualified } \\
\text { Qualified }\end{array}$ \\
\hline Density & 0.8721 & $0.8720-0.8890$ & Qualified \\
\hline Optical rotation & $1.62{ }^{\circ} \mathrm{C}$ & $\left(-32^{\circ} \mathrm{C}\right)-\left(14^{\circ} \mathrm{C}\right)$ & Qualified \\
\hline Refractive Index & 1.487 & $1.4853-1.4920$ & Qualified \\
\hline
\end{tabular}


Table 2. Formulation of Lotion

\begin{tabular}{lcccc}
\hline \multirow{2}{*}{\multicolumn{1}{c}{ Ingredients }} & \multicolumn{5}{c}{ Concentration (\% w/w) } \\
\cline { 2 - 5 } & Base & Formula I & Formula II & Formula III \\
\hline Essential oil of red ginger & - & 2.5 & 5 & 7.5 \\
\hline PEG-40 hydrogenated castrol oil & 24.5 & 24.5 & 24.5 & 24.5 \\
\hline Caprylic & 5 & 5 & 5 & 5 \\
\hline Ethanol & 5.25 & 5.25 & 5.25 & 5.25 \\
\hline Glycerin & 5.25 & 5.25 & 5.25 & 5.25 \\
\hline Methyl paraben & 0.18 & 0.18 & 0.18 & 0.18 \\
\hline Proph paraben & 0.02 & 0.02 & 0.02 & 0.02 \\
\hline Distilled water & 59.8 & 57.3 & 54.8 & 52.3 \\
\hline
\end{tabular}

evaluate the presence of granules or particles which were not evenly mixed. $\mathrm{pH}$ was measured using digital $\mathrm{pH}-$ meter. Viscosity was measured using Brookfield viscometer (DV1-Prime ${ }^{\circledR}$ ). Irritation test was conducted by applying lotion in the back of the hand for 24 hours. The presence of roughening, itching and redness on the skin were observed. ${ }^{8,9}$

\section{Results and Discussion}

Distillation process of $10 \mathrm{~kg}$ of red ginger resulted in $24 \mathrm{ml}$ of essential oils. We found that our red ginger essential oil fulfilled all the requirements of Indonesian National Standard No. 06-1312-1998, indicating that this essential oil had good quality. The result can be seen in the Table 1 .

Results indicated that lotion containing 7.5\% of red ginger essential oil exerted the strongest activity in inhibiting $P$. acnes (inhibition zone $12.4 \mathrm{~mm}$ ) and S. epidermidis (inhibition zone $29 \mathrm{~mm}$ ). The lowest anti-bacterial activity was shown by formula I, which contained

Table 3. Anti-bacterial Activity of Red Ginger Essential Oil Lotion

\begin{tabular}{|c|c|c|c|c|c|}
\hline \multirow{2}{*}{$\begin{array}{l}\text { Bacteria } \\
\text { P. acnes }\end{array}$} & \multirow{2}{*}{$\frac{\text { Sample }}{\text { Positive control }}$} & \multicolumn{3}{|c|}{ Inhibition Zone (mm) } & \multirow{2}{*}{$\frac{\text { Mean }(\mathbf{m m})}{17.3}$} \\
\hline & & 18 & 17 & 17 & \\
\hline & Negative control & 0 & 0 & 0 & 0 \\
\hline & F0 & 0 & 0 & 0 & 0 \\
\hline & F1 & 8 & 8 & 8 & 8 \\
\hline & F2 & 16 & 17 & 16 & 16.3 \\
\hline & F3 & 30 & 28 & 29 & 29 \\
\hline \multirow[t]{6}{*}{ S. epidermidis } & Positive control & 18 & 17 & 17 & 17.3 \\
\hline & Negative control & 0 & 0 & 0 & 0 \\
\hline & F0 & 0 & 0 & 0 & 0 \\
\hline & F1 & 7 & 7 & 7 & 7 \\
\hline & $\mathrm{F} 2$ & 9 & 8 & 8 & 8.3 \\
\hline & F3 & 12 & 13 & 12 & 12.3 \\
\hline
\end{tabular}



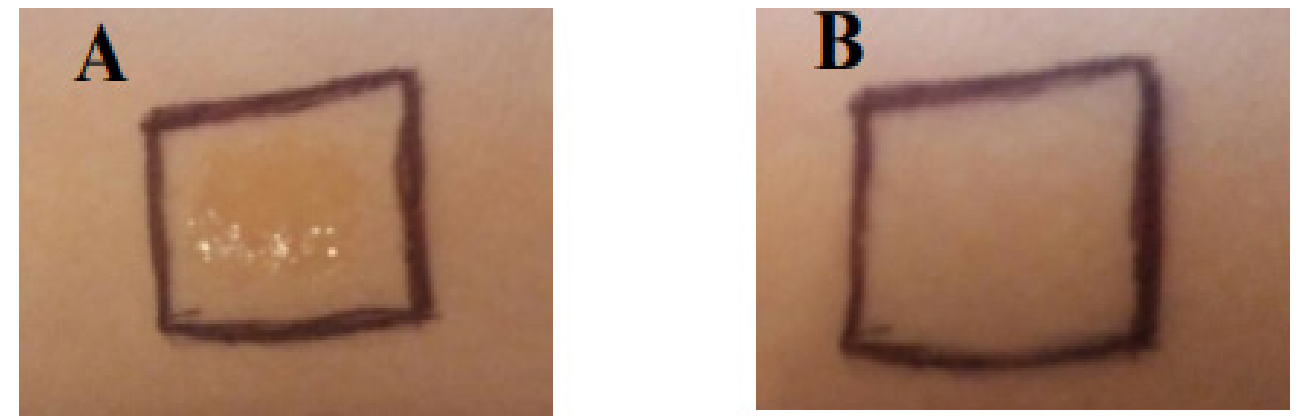

Figure 1. Results of the Skin Irritation Test

A: Skin Condition at Initial Application of Lotion.

B: Skin Condition After 24 Hours Post-Application

$5 \%$ of red ginger essential oil. Formula III had greater inhibition zone compared to positive control against $P$. acnes, but had slightly smaller inhibition zone against $\mathrm{S}$. epidermidis.

Organoleptic examination was intended to evaluate physical properties of the lotion. Results showed that the lotion was yellow, had distinctive aroma of ginger, and had no sediment. Homogeneity test was performed since it is critical to ensure the active substances are dispersed evenly in the base formula. Results showed that the lotion was homogeneous and met the desired criteria.

The degree of acidity $(\mathrm{pH})$ is a very important parameter in a cosmetic product because the $\mathrm{pH}$ of cosmetics influences its absorption on the skin. Cosmetics with very high or low $\mathrm{pH}$ are likely to induce irritation. The results showed that the $\mathrm{pH}$ of the lotion was 7.42. The $\mathrm{pH}$ requirements for cosmetic preparations range from 4.5 to $7.5 .^{10,11}$

Viscosity is a measure of a fluid resistance to flow. Viscosity may affect skin retention of the dosage form. ${ }^{10}$ The results showed that the viscosity of the lotion was $526 \mathrm{cP}$, which fulfilled the requirement from of Food and Drug Administration (viscosity of a good lotion should be $<30,000 \mathrm{cP}) .{ }^{12}$

Irritation test was performed to evaluate the occurence of side effects on the skin. The 24-hours observation showed that the lotion did not cause itching and inflammaiton of the skin, implying that the formula did not induce skin irritation. Further study is encouraged to evaluate long-term stability and effectiveness of red ginger essential oil lotion.

\section{Conclusions}

Anti-acne lotion containing 7.5\% of red ginger essential oil was effective to control acne inducing bacteria and fulfilled the required standards.

\section{Acknowledgement}

None declared.

\section{Funding}

None.

\section{Conflict of interest}

None declared.

\section{References}

1. Kraft J, Freiman A. Management of acne. Canadian Medical Journal. 


$$
\text { 2011;183(7):E430-E435. }
$$

2. Liu Q, Meng X, Li Y, Zhao CN, Tang GY, Li HB. Antibacterial and antifungal activities of spices. International Journal of Molecular Science. 2017;18(6):1283.

3. Kim HS, Park HD. Ginger extract inhibits biofilm formation by Pseudomonas aeruginosa PA14. PLoS One. 2013;8(9):e76106.

4. Swamy MK, Akhtar MS, Sinniah UR. Antimicrobial properties of plant essential oils against human pathogens and their mode of action. Evidence-Based Complementary Alternative Medicine. 2016;2016:3012462.

5. Chouhan S, Sharma K, Guleria S. Antimicrobial activity of some essential oils: Present status and future perspectives. Medicines (Basel). 2017;4(3):58.

6. Bellik Y. Total antioxidant activity and antimicrobial potency of the essential oil and oleoresin of Zingiber officinale Roscoe. Asian Pacific Journal of Tropical Disease. 2014;4(1):40-44.

7. Indriati. Formulation and effectiveness evaluation of Nothopanax scutellarium and Apium graviolens lotions on hair growth in rabbit. 2014. Thesis. University of Pancasila: Jakarta.

8. Lee SH. Evaluation of acute skin irritation and phototoxicity by aqueous and ethanol fractions of Angelica keiskei. Experimental Therapeutic Medicine. 2012;5(1):45-50.

9. Hussain Shah SN, Hussain T, Ullah Khan I, Asghar S, Shahzad Y. Formulation study of topically applied lotion: in vitro and in vivo evaluation. Bioimpacts. 2013;3(1):11-19.

10. Chang RK, Raw A, Lionberger R, Yu L. Generic development of topical dermatologic products: formulation development, process development, and testing of topical dermatologic products. American Association of Pharmaceutical
Scientsist Journal. 2012;15(1):41-52.

11. Shukr MH, Metwally GF. Evaluation of topical gel bases formulated with various essential oils for antibacterial activity against methicillin-resistant Staphylococcus aureus. Tropical Journal of Pharmaceutical Research. 2013; 12 (6): 877-874.

12. Food and Drug Administration (FDA). Guidance for industry bioanalytical method validation. 2001. Center for Drug Evaluation and Research, Rockville, MD, USA. PP 6. 